\title{
Environmental Governance and National Preparedness towards 2030 Agenda for Sustainable Development : A Tale of Two Countries
}

\author{
M. Monirul AZAM ${ }^{1,2 *}$ and Mahesti OKITASARI ${ }^{2}$ \\ ${ }^{1}$ Department of Law, University of Chittagong, Bangladesh, \\ and Graduate School of Decision Science and Technology, Tokyo Institute of Technology \\ 2-12-1 Ookayama, Meguro-ku, Tokyo 152-8550, Japan \\ ${ }^{2}$ United Nations University-Institute for the Advanced Study of Sustainability \\ 5-53-70 Jingumae, Shibuya, Tokyo 150-8925, Japan \\ *email:azam@unu.edu
}

\begin{abstract}
Sustainable Development Goals (SDGs) have been adopted under the 2030 Agenda for Sustainable Development and act as a successor to the Millennium Development Goals (MDGs). It is therefore important to build on the MDGs' achievements and address gaps and weakness that remain unresolved, thereby preparing properly for the 2030 Agenda. Despite the remarkable progress of Bangladesh and Indonesia towards many of the MDGs, there is inherent tension regarding the securing of a successful sustainable trajectory. Gaining environmental sustainability while aiming for inter-linkages and synergies between environmental, social and economic dimensions has remained an unresolved issue as both countries have more or less implemented development efforts in isolation, with inadequate consideration of the potential impacts on the environment. This paper, therefore, seeks to address gaps in environmental governance in both countries for gaining environmental sustainability and for ensuring national preparedness towards the SDG implementation. With that in mind, this article presents a diagnostic status of the current progress on environmental governance in Bangladesh and Indonesia using development indicators of progress towards the MDGs and their determinants in relation to environmental sustainability. The comparison of these two cases provides fruitful insights for drawing lessons on how environmental governance needs to be addressed at the level of individual low- and middle-income countries for their preparedness and transition to the SDGs.
\end{abstract}

Key words: environmental governance, Millennium Development Goals(MDGs), Sustainable Development Goals(SDGs), sustainability

\section{Background}

The MDGs are a set of numerical and time-bound targets for the period of 2000-2015, taking 1990 as the base year to reduce extreme poverty, disease and deprivation of the world's poorest people. The first seven goals intended to be pursued by developing countries to deal with poverty, disease and environmental degradation, while the eighth goal was essentially a commitment to a global partnership between rich and poor countries to achieve the first seven goals (UN, 2000). Based on the outcome of the United Nations Conference on Sustainable Development, the Open Working Group (OWG) was established on 22 January 2013 by the United Nations General Assembly (UNGA) comprising $30 \mathrm{UN}$ Member States to ensure an inclusive and transparent intergovernmental process (UN, 2012). Based on extensive negotiations, the OWG proposed, 17 goals and 169 targets (UN, 2014a). The HLPF was established to succeed the Commission on Sustainable Development as per the outcome of Rio+20 in order to follow up and review the progress in implementing sustainable development commitments (UN, 2013a). Further, the UN Secretary-General appointed a HLP as an initiative to provide recommendations for the new SDG framework (UN Press Release, 2012). The HLP report emphasized five "key transformations": "(a) leave no one behind; (b) put sustainable development at the core; (c) transform economies for jobs and inclusive growth; (d) build peace and effective, open and accountable public institutions; and (e) forge a new global partnership" (UN, 2013b). After extensive negotiations and receipt of stakeholders' submissions and recommendations from several $\mathrm{UN}$ and non-UN bodies, the 2030 Agenda for Sustainable Development was finally adopted with a set of 17 goals 
and 169 targets during the UNGA summit held on September 25-27, 2015.

Despite good progress on several MDGs, most developing countries are still lagging in terms of sustainability and governance. Therefore, it is important to review MDGs achievements and address gaps and weakness that remain unresolved, thereby ensuring proper preparedness towards the 2030 Agenda. This study analyses the performance of Indonesia and Bangladesh, considering that both countries have made remarkable progress towards many of the MDGs. Lessons learnt from their methods and struggle for development while trying to secure a successful sustainable trajectory could become an example to many developing countries and the Least Developed Countries (LDCs) for transformation towards attaining the SDGs. Among the LDCs, the experiences of Bangladesh are remarkable, as despite having serious climate change and other environmental vulnerabilities along with a huge poor population and infrastructural limitations, the country has fared well in achieving most of the MDGs and is considered one of the pioneers in integrating climate change policies in national development planning (Bhattacharya, 2013). On the other hand, Indonesia's experience with the MDGs and challenges in dealing with disparities between local governments, nurturing synergies between national and sub-national efforts and specifically institutional cooperation and issues of governance could also help other developing countries be better prepared for the SDGs (UN, 2014b).

Gaining environmental sustainability while aiming for inter-linkages and synergies between environmental, social and economic dimensions has remained an unresolved issue, as Bangladesh and Indonesia more or less implemented development efforts in isolation, with inadequate consideration of the potential impacts on the environment. This article, therefore, seeks to address gaps in environmental governance in both countries for gaining environmental sustainability and ensuring national preparedness towards the 2030 Agenda. With this in mind, this article presents a diagnostic status of the current progress on environmental governance in Bangladesh and Indonesia using development indicators towards achieving the MDGs and their determinants in relation to environmental sustainability. Table 1 reflects the progress towards several targets under the MDGs by Bangladesh and Indonesia. The comparison of these two cases provides fruitful insights for drawing lessons on how environmental governance needs to be addressed at the level of individual low- and middle-income countries for their preparedness for and transition to the 2030 Agenda.

\section{The Case of Indonesia}

MDG-7 for ensuring environmental sustainability is recognised as one of the most challenging goals to reach in developing countries, Indonesia in particular, due to the intensity of its environmental issues and its strategic importance to the environmental sustainability of the region (UN CCA, 2004). As a vast archipelago with great geographical variety, Indonesia owes its past decades of macro-economic growth to its natural resources. With two thirds of the Indonesian population depending on natural resources for their livelihoods (UN CCA, 2004), continuing degradation of the natural environment poses a threat to their socioeconomic situation. Indonesia was one of the first countries to issue a national strategy for sustainable development following the Earth Summit 1992 (BAPPENAS, 1993). However, regardless of the central government's efforts to promote environmental sustainability and various support measures from international donors for policy and capacity development, Indonesia's administrative and regulatory frameworks are often criticized for failing to meet the demands of sustainable development (World Bank, 2008). Practices on the ground are often contradictory, as the country sets to expand its economic development, e.g., plans to integrate the principles of environmental sustainability into policies, including protecting natural resources, are contradicted by plans to increase industry's ability to access and utilize the same resources.

\subsection{Progress towards the MDGs and Environmental Sustainability Targets}

Regarding MDG attainments, overall, Indonesia has made significant progress towards goals related to poverty, education, communicable diseases, and gender equality. On MDG-1, Indonesia successfully reduced the proportion of people living under the national poverty line from 15.10 percent (1990) to 11.25 percent (2014). Its efforts to achieve universal primary education have also been in step with the MDGs through the implementation of basic nine-year education and increasing the Net Enrolment Ratio in primary education to 96.0 percent (2013). On the other hand, reduction of child mortality (MDG-4) and improvement of maternal mortality (MDG-5) are unlikely to be achieved in Indonesia. Child mortality has been reduced from 97 (1991) to 40 per thousand live births (2012), yet reduction of maternal mortality by three-quarters will still require more efforts.

As far as MDG-7 is concerned, Indonesia has attained mixed results in meeting the targets on environmental sustainability. It is not on track to reach the target for reversing the loss of environmental resources, despite making good progress on phasing out Ozone Depleting Substances (ODS). No significant progress has been made towards reducing and halting deforestation, with recent statistics showing that Indonesia has emitted more carbon dioxide in 2014 compared to 2000 (BAPPENAS, 2014). The proportion of the population living in slums and in need of proper housing is progressing slowly at 9.12 percent (2014), down from 20.75 percent (1993), but still above the given target of 6.0 percent.

While some of the MDG-7 targets have been achieved and many programs have been established, 
Table 1 MDGs: Bangladesh (BD) and Indonesia (IDN) progress at a glance (2015).

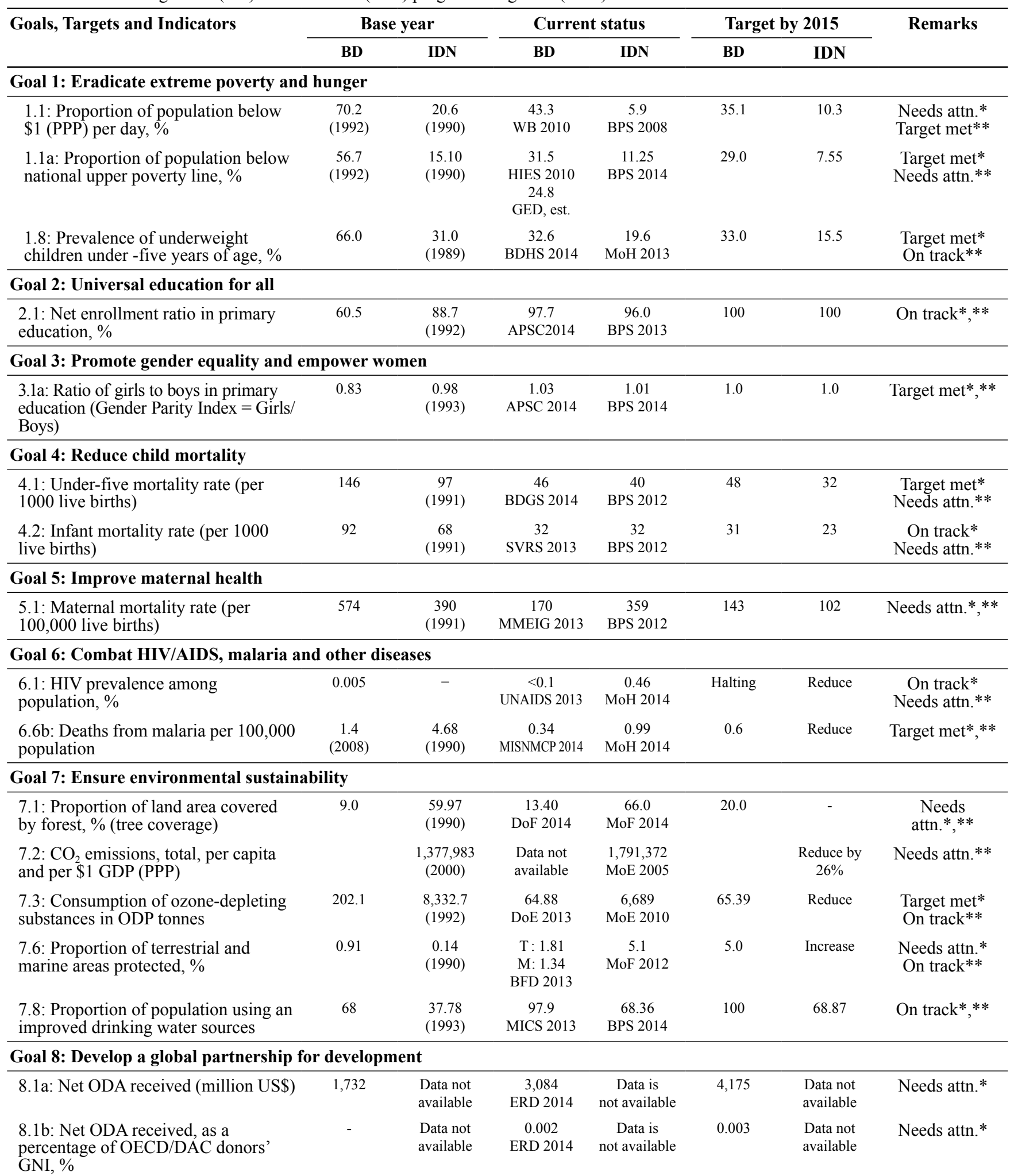

Note: *Bangladesh, **Indonesia.

Indonesia is still facing growing challenges in steering its environment towards the desired sustainable future. Most of all, its key environmental governance problems and opportunities center around weak institutions and a policy framework for environmental protection created with a lack of clear mandates between levels of governments, weak enforcement and inadequate technical capacity to govern the environment. Compared to its progress towards the welfare-related MDGs, Indonesia has a long way to go to attain MDG-7. Aside from structural, institutional and political challenges, a lack of government priority contributes to the slow progress towards achieving MDG-7. Provision of drinking water and basic sanitation is not a development priority for the 
provincial and local governments.

\subsection{The National Development Plan and Mainstreaming Environmental Sustainability}

Understanding the government's priorities and the implications of delegating program delivery to sub-national governments is needed for successful integration of environmental sustainability in a country undergoing decentralization like Indonesia. The comprehensive framework to streamline the MDGs in Indonesia's planning system allows the central government to strengthen MDGs target-setting down to the local level, yet it has been less successful in mainstreaming sustainability issues. Critics have pointed out the lack of integration of environmental consideration at the planning levels, with only verbal expressions of agreement, and the lack of a financing scheme (UNEP, 2003; World Bank, 2008). Specifically on the financing issue, regardless of the central government's improvement on the allocation of the MDG fund at the central and sub-national levels, it has been largely ignoring the environmental sector. For example, in the 2013 Specific Allocation Fund, forestry and environmental funding accounted for only 3.6 percent (Ministry of Finance Regulation 201/ PMK.07/ 2012). In comparison, the budget for education was mandated by Law 20/2003 and accounts for 20 percent of the national budget.

Environmental consideration will remain merely rhetorical as long as it is not the government's main concern, resulting in a lack of initiatives to set the proper institutional structure for delegating programs. The Indonesian government's five-year strategic policy frameworks stress the importance of the MDGs through the government's commitment to enhancing the people's welfare (BAPPENAS, 2004; 2010). Consequently, the MDGs in Indonesia are overwhelmingly seen as a social improvement program as they focus more on social and human-welfare-related goals rather than environmental issues. Indonesian MDGs programs on environmental sustainability, therefore, focus on delivering public infrastructure rather than developing programs to protect and improve the environment. Regarding the implementation and investment processes, the central government has failed to integrate environmental consideration at the programmatic levels as it leaves out the relevant sectoral ministries, e.g., Agriculture, Marine and Fisheries, and Forestry, in collaborative processes.

\subsection{Governance: Enforcement, Capacity Constraints and Synergy}

The shortcomings of Indonesian MDG environmental policies also lie in their enforcement mechanism. Prior to the MDGs, there was no comprehensive environmental assessment. The Indonesian government imposed environmental protection on industrialization in 1986 through the enactment of an EIA law. In 1991, the central government made EIA compulsory prior to obtaining a business permit, effectively applying EIA as Indonesia's first environmental policy instrument. Regarding its implementation, however, EIA has been criticized for lack of legal enforcement due to a high number of violations (Susilo \& Rhiti, 2001). A development paradigm which prioritizes industrial growth, resource utilization and increased consumption over environmental protection is also pointed out as an important cause of its failure (Young, 1999). In response to these shortfalls, the most recent development in safeguarding the environment was the 2009 EPMA, which aimed to provide a stronger legal basis for the EIA system in the decentralized framework. Nonetheless, to improve enforcement, the government still needs to identify gaps between the EPMA framework and subnational administrative procedures and integrate the EPMA further into local planning and permitting processes.

Decentralization poses major challenges for coordination among various levels of government. Most of Indonesia's governance issues are rooted in the distribution of revenue powers and spending responsibilities among the central and subnational governments. Many of the MDG-7 targets are accounted under the jurisdiction of local governments. The central government might draft various environmental sustainability programs, but most of those programs fail to be implemented due to conflicting financing priorities and capacities at the local level.

Incoherent policies also serve as a major obstacle in implementing MDG environmental policies, largely due to the administrative decentralization. There are gaps between policy and implementation, conflicting national and subnational priorities, and weak vertical and horizontal integration (World Bank, 2008). Local governments often suffer from poorly developed vertical relationships with weak anchorage in national politics. As a consequence, economically driven decisions from the central government overshadow local environmental policies or vice versa (Fredriksson \& de Kam, 1999). Weak relations with other local stakeholders, such as the legislative and private sectors, create problems for local governments in implementing and monitoring their environmental programs and seeking financial support.

\section{The Context of Bangladesh}

Bangladesh has achieved several MDGs targets, for example, reducing the poverty headcount and poverty gap ratio, attaining gender parity in primary and secondary education, reducing the under-five mortality rate, containing HIV (Human Immunodeficiency Virus) infections with access to antiretroviral drugs, having children under five sleep under insecticide-treated bed-nets, and achieving the detection and cure rates of TB (Tuberculosis) stipulated under DOTS (Directly Observed Treatment, Short-Course) (GOB, 2014). It has also made good progress in reducing the prevalence of underweight children, increasing enrollment in primary schools, lowering the infant mortality rate and maternal mortality ratio, improving immunization coverage and reducing the incidence of communicable diseases (GOB, 
2014). Due to several ongoing environmental governance problems, however, the country failed to make good progress in the field of environmental sustainability, which could frustrate progress in other sectors as well. That is why it is important for Bangladesh to review carefully progress towards the MDGs in general and MDG-7 in particular, on environmental sustainability through mainstreaming and integrating sustainable development in the sectors of vital importance in Bangladesh to make a smooth transition towards the 2030 Agenda.

\subsection{Lessons Learnt from the MDGs with special reference to MDG-7 on Environmental Sustainability}

Bangladesh has made commendable progress with respect to MDG-1 for eradication of poverty and hunger. It has sustained a GDP growth rate of 6 percent or above in recent years, and that has played a positive role in eradicating poverty. In terms of MDG-1, other remarkable progress has been bringing down the poverty gap ratio to 6.5 against the 2015 target of 8.0, and halving the population living below the poverty line (from 56.7 percent to 29.0 percent), already achieved by 2012 (GOB, 2014). Regarding MDG-2, significant progress has been made in increasing equitable access to education, reducing dropouts and improving completion of the educational cycle. Bangladesh has already achieved gender parity in primary and secondary enrollment as per the targets of MDG-3. There has been steady improvement in the social and political empowerment scenario of women in Bangladesh.

In terms of MDG-4, Bangladesh is on track towards meeting the targets measured by three different indicators, i.e., under-five mortality rate, infant mortality rate and immunization against measles. Bangladesh has also met remarkable progress on most of the targets under MDG-5 on improving maternal health and has also maintained significant progress in combating HIV/AIDS (Acquired Immune-Deficiency Syndrome), malaria and other diseases under MDG-6 (GOB, 2014). The average rate of maternal death declined about 3.3 percent per year, compared with the average annual rate of reduction of 3.0 percent required for achieving the MDG in 2015. On the other hand, the prevalence of HIV/ AIDS in Bangladesh is currently less than 0.1 percent and thus is still below an epidemic level. The proportion of children under five with fever who are treated with appropriate anti-malarial drugs was recorded at 89.50 percent in 2013 and the target to achieve 90 percent by 2015 has almost been met (GOB, 2014).

Despite good progress towards most of the MDGs, Bangladesh is facing considerable sustainable development challenges, which have also resulted in slow progress on MDG-7. For example, only 13.40 percent of land in Bangladesh has tree cover with a density of 30 percent or above and the area with tree cover is much lower than the target set for 2015. Since 1991, there has been a steady increase in $\mathrm{CO}_{2}$ emissions in Bangladesh because of increasing development interventions and activities (GOB, 2014). Again, climate change is the major challenge to attaining sustainable development in Bangladesh. It is widely recognized that climate change will affect many sectors, including water resources, agriculture and food security, ecosystems and biodiversity, human health and coastal zones in Bangladesh (Afrin, 2012; BCAS, 2012). Even though the government has tried to achieve the MDG targets by the deadline, climate change has acted as a big developmental and environmental threat to Bangladesh that has jeopardized attainment of many MDGs and could also become a major barrier to attaining SDGs in the future (BCAS, 2012).

Despite reports by the Bangladesh government, local UN based organizations and local media reports frequently highlight MDG success stories in Bangladesh (GOB, 2012), very few reports address the difficulties or challenges of achieving other unmet MDG targets, for example environmental sustainability. Nevertheless, it is important to learn from present developmental challenges and weakness and use these experiences to avoid future failures in the relevant sectors.

One of the leading environmental experts in Bangladesh, Dr. Atiq Rahman, stated, "Independent assessment, however, casts doubt about the prospect of achieving the MDGs in their totality in the country. At least two impediments are obvious. One is the country's institutional inability to effectively implement policies and programs, given the abysmal record of poor governance in terms of inefficiency and corruption, lack of transparency and accountability, and, above all, poor law and order conditions. The other constraint is that of limited domestic resources that will fall far short of the requirement to implement programs to achieve the MDGs" (Rahman, 2015). He further added, "The country will need a lot more resources to achieve some non-MDG targets such as the development of infrastructure, improved management of power and ports, and achievement of a better investment climate, without which economic growth and consequently, poverty alleviation efforts will suffer" (Rahman, 2015). Therefore, while making the transition to the SDGs, it will be important for Bangladesh to review its state of governance to streamline sustainable development in national development planning and to improve governance by addressing issues of capacity constraint, weak enforcement and lack of synergy.

\subsection{Mainstreaming Sustainability in national developmental planning, laws and policies}

Despite having a good number of environmental laws, policies, rules and regulations in Bangladesh such as National Environmental Policy, 1992, National Environmental Action Plan, 1992, Environmental Conservation Act, 1995 (amended in 2000 and 2002), Environmental Conservation Rules, 1997, National Conservation Strategy 1997, Environmental Court Act 2000 (amended in 2002) and the existence of MOEF with a number of related organizations under its jurisdiction, 
the institutional base of environmental governance in Bangladesh continues to remain weak, fragmented and insufficient to meet the enormous environmental challenges the country faces in the future (World Bank, 2006). The reason behind the failure of the enormous amount of laws and policies is the lack of coherence among the different rules and institutions and also a lack of priority for sustainable development and climate change issues until the last few years.

Without climate resilience and mainstreaming of sustainability across different laws and policies, no development efforts will have lasting positive impacts in Bangladesh. The implementation of 2030 Agenda in Bangladesh, therefore, should have robust climate resilience components and mainstream sustainability in national developmental planning, laws and policies along with providing effective governance and synergy between institutions and policy coherence between global, regional, national and local actions (Azam, 2011).

The formulation and adoption of the National Sustainable Development Strategy (2011-2021) is a step in the right direction (GOB, 2013a). It is also remarkable that the Government of Bangladesh has also decided to establish a sustainable development monitoring council and sustainable development board to ensure mainstreaming of sustainable development across different ministries and also in broader national economic planning and development activities (GOB, 2013a). Furthermore, the establishment of the CCU to deal with climate change adaptation and mitigation also provides a focal point for inter-ministry cooperation on environmental actions (GOB, 2013a). The CCU launched its activities in January 2010 under the MOEF. In addition, the BCCT was established on 24 January 2013 as per the direction of the Climate Change Trust Act, 2010, under the MOEF (GOB, 2013a).

It is worth noting that MOEF in close cooperation with a wide range of NGOs and international agencies, such as UNDP, formulated NEMAP in the early 1990s. NEMAP has the distinction as one of the world's largest participatory plans. The Government of Bangladesh has also adopted the BCCSAP and NAPA to address climate change impacts in the country. These have been recognized internationally as major contributions to the response strategies to climate change. Regardless of this achievement, there have been weaknesses in institutionalization and implementation of the rules and regulations of Bangladesh.

\subsection{Governance: Capacity Constraints, Enforcement and Synergy}

In general, there has been an increased awareness about sound environment and conservation of natural resources among the general people, both in cities and rural areas in Bangladesh. The government of Bangladesh has revised their relevant policies and enacted rules and regulation in these areas. In some cases, NGOs and civil society organizations are working as close partners and sometimes as pressure groups for better management of natural resources, conservation of environment and pollution control. Due to a lack of proper enforcement and required technical, financial and human resourcebased capacity constraints, environmental problems have been aggravated in Bangladesh and environmental sustainability still remains an unattainable goal there.

Environmental governance is vital to making government institutions, private sectors and individuals act within the limits of conservation of natural resources and the environment and avoiding unnecessary pollution of land, water, air and ecosystems. In Bangladesh, however, the private sector (industries, trade and businesses) often fails to follow environmental rules and regulations. The protection of environmental resources (forests, hills, wetlands, rivers and biodiversity) and urban environments remains the greatest challenge due to lack of political commitment, skilled human resources and institutional capacity for ensuring proper enforcement of rules and regulations (Rahman, 2015). It will be impossible for Bangladesh to meet the SDGs in the future, however, without strict adherence to environmental acts, by-laws and environmental impact assessment guidelines or in the absence of implementation by all agencies, including the government, private sector, civil society and all citizens.

There is an urgent need for improving internal governance within government institutions, for example, in the Department of Environment, Forest Department, Bangladesh Water Development Board, Local Government Division, Rural Development Board, city corporations and various ministries. The MOEF is supposed to be the regulatory body and focal point with its agencies for environmental and sustainability issues. There have been instances, however, where political influences have forced governmental institutions to work against laws related to the protection of the environment (Rahman, 2015).

All governmental agencies in Bangladesh need to demonstrate fairness, responsibility, responsiveness and transparency as key pillars of governance (Azam, 2006). As stated in one study, "powerful groups should not be privileged to destroy the environment. Those who are grabbing land, wetlands and forest resources illegally and polluting the environment must be punished in accordance with the law. The ministries, departments and administration must work under the cover of existing laws, independently and boldly. The political process must demonstrate support to the institutions; only then environmental governance will be enhanced" (Rahman, 2015). Civil society groups and NGOs should mobilize public opinion and put pressure on the government and the political process to ensure effective monitoring and implementation of relevant environmental laws and policies (Rahman, 2015). The private sector in Bangladesh should not be allowed to harm the environment and disturb social equilibrium while performing economic activities.

Thus, the current status of environmental governance in Bangladesh indicates that to attain significant outcomes from the SDGs, priority needs to be given to several critical 
areas, such as increasing productive capacity; enhancing access to knowledge and technology; strengthening trade, human and social development; improving governance and institutional capacities; increasing resilience to economic and natural shocks; mitigating climate change impacts; and enhancing the volume and quality of resource support (Azam, 2011; Rahman, 2015).

\section{Transformation for the 2030 Agenda for Sustainable Development}

The MDGs have raised public awareness and helped, albeit in a limited way, to mobilize actions to support environmental protection in Bangladesh and Indonesia. Although the two countries have different levels of economic, social and environmental challenges, they both need better enforcement of regulatory frameworks and progress in redistribution of wealth and protection of rights, and the success of future SDGs will rely on improved policy coherence among all levels. Therefore, both countries need to adopt affirmative policies to address inequality in terms of regulatory and budgetary constraints to improve policy coherence at the local level.

The Government of Bangladesh held the first National Expert Level Consultation Conference on November 10, 2012, to identify gaps and challenges that exist in relation to sustainable development and to formulate preliminary goals, targets and indicators for the SDGs (UNB, 2013). There were several follow up meetings with national experts, stakeholders and also local UN bodies leading to adoption of a national document on a sustainable development agenda proposing 11 goals, 58 targets and 241 indicators (GOB, 2013b). In the context of Bangladesh, despite having major opportunities for intervention to reduce greenhouse gas emissions in power generation, transportation, industrial production, agriculture, forestry and other sectors, there is a lack of facilitating technology, institutional support and dedicated financing (Azam, 2006). Therefore, while moving towards the 2030 Agenda, Bangladesh needs to initiate rapid implementation of sustainable energy programs and employ technologies that could improve the quality of the environment and generate developmental benefits as well (Azam, 2011). The Government of Bangladesh rightly acknowledges that mainstreaming of poverty-environment-climate change in local and national development planning with dedicated programming, implementation and financing provisions is vital to achieving sustainable development (GOB, 2013b).

In the SDG preparatory context, Indonesia held its first National Consultation on the 2030 Agenda on February 20-21, 2013. Prior to the meeting, regional consultations with the sectorial ministries, local UN bodies and civic society were conducted through the second half of 2012. In general, the Government of Indonesia has opposed creating SDGs outside the MDGs, preferring to strengthen the existing MDG targets instead. Given the challenges and constraints to achieving the MDGs, Indonesia has stressed the importance of more action-oriented indicators and technical and financial assistance to accelerate the implementation of its sustainable environmental programs.

While we can agree that the success of implementing the 2030 Agenda will depend on the quality of governance, the key challenge will be to find an appropriate mode of governing for each country that models the complex institutional and incentive problems in the implementation and monitoring processes. Decentralization and increasing local accountability are one pathway towards better program implementation, yet it would be misleading without considering the precise financing mechanisms that accompany decentralization (Bardhan, 2002; Bardhan $\&$ Mookherjee, 2006). The existing Indonesian financing scheme, for example, will require wider local capture in order for local governments to be able to finance many of their environmental programs. At the national level, more space for additional spending and provision of environmentally sensible incentives will be needed (World Bank, 2014). The recent elimination of fuel subsidies in January 2015 should provide those to some extent.

To conclude, both Bangladesh and Indonesia, need to ensure strong vertical and horizontal relations and policy coherence and cooperation at all levels of government for effective implementation of the multidimensional aspects of the 2030 Agenda. As implementation of the SDGs will mostly depend on political will and wisdom, efforts to increase the commitment of actors in the central and subnational governments will be crucial. It will also be important to improve the knowledge base about the SDGs not only among governmental officials, but also among legislators, officials at the grass- roots level, the private sector, civil society members, universities and the media to attain sustainability for all.

\section{Acknowledgements}

The authors would like to express profound gratitude to the Japan Society for Promotion of Science (JSPS) for fellowships and grants during the preparation of this papar.

\section{References}

Azam, M.M. (2006) Establishment of the WTO and challenges for the legal system of Bangladesh. Macquarie Journal of Buisiness Low., 3, 23.

Azam, M.M. (2011) Climate change resilience and technology transfer: The role of intellectual property, Nordic Journal of International Law, 80(4): 485-505.

Afrin, D.T. (2012) Climate Change and Bangladesh.

$<$ http: / / www.climateemergencyinstitute.com/ bangladesh_1_ affrin.html $>$ (accessed 12 Apr 2015).

Bhattacharya, D. et al. (2013) Attaining the MDGs How Successful are the LDCs? Centre for policy dialogue.

$<$ http://cpd.org.bd/wp-content/uploads/2013/09/Attaining-theMDGs-in-LDCs.pdf $>$ (accessed 30 Oct 2015).

Bangladesh Centre for Advanced Studies (BCAS) (2012) D. Mallick, A. Amin and A. Rahman, Case Study on Climate Compatible Development (CCD) in Agriculture for Food Security in Bangladesh.

Bardhan, P. (2002) Decentralization of governance and development. 
Journal of Economic Perspectives, 16(4): 185-205.

Bardhan, P. and D. Mookherjee (2006). Decentralization and accountability in infrastructure delivery in developing countries. The Economic Journal, 116(508): 101-127.

Government of Bangladesh (GOB) (2012) Ministry of Environment and Forest, "Rio+ 20: Bangladesh Report on Sustainable Development".

Government of Bangladesh (GOB) (2013a) Ministry of Environment and Forest National Sustainable Development Strategy 2010-21 (NSDS).

Government of Bangladesh (GOB) (2013b) Post 2015 Development Agenda: Bangladesh Proposal to UN, Planning Commission of Bangladesh.

Government of Bangladesh (GOB) (2014) Ministry of Planning Millennium Development Goals, Bangladesh Country Report, 2013.

Fredriksson, G.M. and M. de Kam (1999) Strategic Plan for the Conservation of the Sungai Wain Protection Forest, East Kalimantan, Indonesia. International Ministry of Forestry and Estate Crops: Tropenbos Kalimantan Project. Balikpapan: Tropenbos Kalimantan Project: 1-38.

National Development Planning Agency (BAPPENAS) (1993) 1993 Broad State Guidelines and the $6^{\text {th }}$ Five Year Development Plan.

National Development Planning Agency (BAPPENAS) (2004) The National Government Strategic Plan 2004-2009.

National Development Planning Agency (BAPPENAS) (2010) The National Government Strategic Plan 2010-2014.

National Development Planning Agency (BAPPENAS) (2014) Report on the Achievement of the Millennium Development Goals in Indonesia 2013.

Rahman, D.A. (2015) Environmental Governance and Growth. The Daily Star (March 12, 2015, Dhaka, Bangladesh).

$<$ http: / / www.thedailystar.net/ supplements/ 24th-anniversarythe-daily-star-part-3> (accessed 13 Mar 2015).

Susilo, FX E. and H. Rhiti (2001) Environmental governance in Indonesia. In: IGES, ed., Report of the First Phase Strategic Research on Environmental Governance. IGES.

United Nations (2000) United Nations Millennium Declaration, Resolution 55/2.

United Nations (2012) The Future We Want, Resolution 66/288.

United Nations in Bangladesh (UNB) (2013) On the Post 2015 Development Agenda for Bangladesh.

$<$ http: // www.un-bd.org/ docs/ Post\% 202015\% 20Agenda\% 20 UNCT\%20Report.pdf> (accessed 12 May 2015).

United Nations (2013a) Format and Organizational Aspects of the High-level Political Forum on Sustainable Development, Resolution 67/290.

United Nations (2013b) A New Global Partnership: Eradicate Poverty and Transform Economies through Sustainable Development. The Report of the High-Level Panel of Eminent Persons on the Post-2015 Development Agenda.

United Nations (2014a) Report of the Open Working Group of the General Assembly on Sustainable Development Goals, Resolution 68/970.

United Nations (2014b) Indonesia National Workshop on Sustainable Development Goals (2014).

$<$ http://www.unorcid.org/upload/doc lib/Summary\%20of\%20 Bali\%20SDG\%20Workshop.pdf> (accessed 29 Oct 2015).

United Nations Common Country Assessment (UN CCA) (2004) Indonesia. United Nations Development Group.

United Nations Environment Programme (UNEP) (2003) Indonesia: Integrated Assessment of the Poverty Reduction Strategy Paper: With a Case Study on Sustainable Fishery Initiatives. UNEP.

United Nations Press Release (2012) UNSG Appoints High-Level Panel on Post-2015 Development Agenda, 31 July 2012.

World Bank (2006) Bangladesh Country Environment Report. Dhaka: The World Bank.
World Bank (2008) The Little Green Data Book. Washington, D.C.: The World Bank.

World Bank (2014) Indonesia Economic Quarterly Delivering Change. Washington, D.C.: The World Bank.

Young, M.A. (1999) The primacy of development: environmental impact assessment in Indonesia and Australia. Australian Journal of Asian Law, 1(2): 154-93.

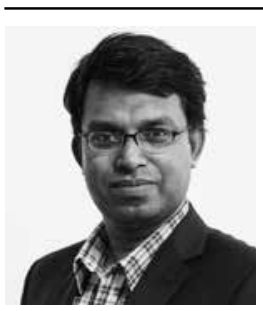

\section{Monirul Azam}

Dr. Monirul AZAM is a JSPS-UNU post-doctoral fellow at the United Nations University-Institute for the Advanced Study of Sustainability (UNU-IAS) along with the Tokyo Institute of Technology. He is also an associate professor in the Department of Law, University of Chittagong, Bangladesh. He taught at the Department of Law, Stockholm University, Sweden as a course director of 'IP and Sustainable Development.' His area of research includes broader 'sustainable development' policy questions in the areas of international law with a focus on intellectual property and international trade issues, climate change, public health, technology transfer and governance. He holds a Ph.D. in International Economic Law from the University of Bern, Switzerland.

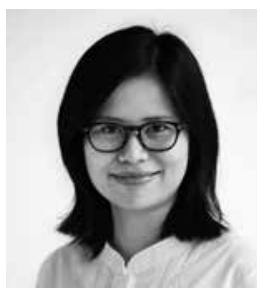

\section{Mahesti OKITASARI}

Dr. OKITASARI is a JSPS-UNU post-doctoral fellow at the United Nations University-Institute for the Advanced Study of Sustainability (UNU-IAS) and Keio University. Her research focuses on the theoretical-empirical study of the planning governance and policy processes, focusing particularly on institutions, collaboration, power and actor relations. She holds a Ph.D. in urban planning from the University of Tokyo, Japan. 